\title{
CITY SPECIALISATION AND DIVERSIFICATION IN SOUTH EAST EUROPE (SEE) COUNTRIES
}

\author{
Ivana Rašić Bakarić, Katarina Bačić, Sunčana Slijepčević
}

\section{Introduction}

Cities are considered centres of economic activity and, presumably, they remain attractive locations for manufacturing firms so as long as benefits agglomeration economies prevail over the costs of agglomeration diseconomies. Agglomeration economies attract firms and labour to co-locate, while agglomeration diseconomies push firms and labour to relocate to decentralised locations (Richardson, 1995). Industry patterns formed across urban landscape of a country or a region will largely depend on the interplay of these opposite forces, as well as on industry- and firm-specific issues. The size of agglomeration and the economic structure may be interrelated and in some economies, mostly larger, patterns of city specialisation emerge. All cities are characterised by being either specialised or diversified, depending on whether their economic activity is concentrated in similar or dissimilar types of production - and larger cities tend to be more diversified (Duranton \& Puga, 2000).

An overriding problem in Urban Economics research in South-East Europe is the lack of data. In the case of ex-Yugoslav countries, we see no regular yearly statistics on cities since the 1990es. The data hindrance is probably the main reason why research in CEE is also mostly focused on regions and not on cities. Research topics in the regional context mostly range within the income convergence/ disparities issue. Results from this research can implicitly shed some light on the issue of city specialisation.

Economic development of cities in the South-East Europe since the end of the World War II can be seen through two distinct economic development periods: a) The fullscale industrial development of cities. Cities expand their borders as economic migrants from all the countries' regions join the wave of rising economic activity; b) The tertiarisation phase upon the breakdown of communism and the onset of social and economic transition to democracy and market economy. Economic planning is quickly dismissed as a relic of socialist planning and many cities are left to cope with the rising unemployment coming from the weakened industries. It must be noted that the deindustrialisation process in the metropolitan regions has started in some cities even before the transition process, in the 1980s, as documented in Croatia's capital development (Svirčić-Gotovac, 2006). However, while western EU economies experienced urban shrinking since the 1970s, CEE countries continued to support industry and neglect service sector up to 1989 which resulted in overgrowth of industrial agglomerations (Rumpel et al., 2013).

The development of metropolitan regions contrasts the development of former industrial cities. The newest indicators of development of metropolitan regions in European transition and post-transition economies available at EUROSTAT and OECD indicate that metropolitan regions have largely converged to the EU average in income per capita and other economic indicators. According to the extensive research of Central and Eastern Europe cities by Lintz et al. (2004), market forces spurred city development, but mostly in the case of metropolitan regions. Urban attraction forces of metropolises have drawn foreign investors and have further strengthen the position of the capital-cities within the national urban system. Dogaru et al. (2014) have found that capital city regions received more greenfield FDI and attracted a wider variety of investments in both sectors and functions.

The fast growth dynamics of metropolitan regions is unmatched by former industrial or industrial \& agricultural regions. To some 
extent, this can explain the level of regional disparities at NUTS level III in the new member states that are significantly higher than in the incumbent members: the average level of the measure of dispersion in the year 2011 in new member states is 35.1 percent, compared to 25.8 percent in incumbent members. Lintz et al. (2004) report the context of the setback of many old industrial cities that hosted important industrial plants through the lower business start-up rate of local population. Lintz et al. (2007) noticed that many old industrial cities in CEE countries, which have been drivers of growth in CEE countries for decades, have been facing major problems (socioeconomic and environmental) since the economic transition and that they have experienced a setback. It could be debated that the reliance of the local population on one or few big industries that have employed the whole city and regional working population has inhibited the entrepreneurial spirit and thus also cities' economic recovery and further growth. New disparities between different CEE cities during transition have been dependent on location, inherited economic structure and environmental quality (Lintz et al., 2007), but also stirred by demographic changes and outmigration (Scott \& Kühn, 2012). While mostly capital cities and regional centres developed (partly due to European union funds), peripheries experienced urban economic decline connected with closure of industrial enterprises (Lintz et al., 2007; Sýkora \& Bouzarovski, 2011).

As pointed out, results from regional research can be useful in learning more about cities in CEE. Regional development policies in European transition economies have been revived with the political and economic desire to join the EU. Evidence on regional specialisation has shown that increase in specialisation in the incumbent EU members was insubstantial (OECD, 1999; 2004), thus risks associated with greater specialisation brought by EU integration as debated by the US economist Krugman (1991), were probably illusory. Recently presented evidence for the new EU transition members has shown that in the case of Central European countries (CEC) changes in the relative regional specialisation are more dynamic than in the incumbent members (Stierle-von Schütz \& Stierle, 2013).

The main aim of this paper is to discern whether patterns in the relative specialisation and diversification of manufacturing industry in 98 SEE (Bosnia and Herzegovina, Bulgaria, Croatia, Serbia, Slovenia and Romania) cities exist, by constructing specialisation and diversification measures over the period 2006-2013. The article is structured as follows: Section 1 provides a literature overview on city specialisation issues, Section 2 describes the dataset, the sample of cities and discusses representativeness issues. In this section measures of specialisation (and diversification) are applied to the dataset, with the purpose to capture the traits of cities' economic structure. Section 3 analyses differences within manufacturing industry across cities in terms of their technological complexity and uses cluster analysis to identify groups of cities on the basis of multivariate data, namely indices of manufacturing-industry specialisation, and city size using population data. These measures enable recognising industrial patterns in urban space throughout countries and the SEE region. Section 4 offers conclusions.

\section{Literature Review}

Specialisation of cities is an important topic in urban economics. Duranton and Puga (1999) summarize the most important findings on diversification and specialisation of cities, mostly coming from city research in the US, in few stylised facts (paraph., p. 2-9): "Both specialised and diversified cities exist; Larger cities tend to be more diversified; Individual city specialisations are stable over time; Most relocations are from diversified to specialised cities." In Henderson (1997) research on diversity and city size, he has found that larger cities (population above 500,000) in the US were more specialised in services and medium-sized cities were more specialised in manufacturing. The latter were also more specialised in mature-industries (textiles, food, pulp and paper) than in new industries on lower levels of aggregation. Duranton and Puga (2005) revealed a shift in city specialisation in the US from sectoral to functional specialisation that came as a result of disintegration of functions: management was located in larger cities and production functions in smaller cities. Davies and Henderson (2008) found that this separation is useful for headquarters because of the availability of differentiated local suppliers and because of the presence of the other headquarters. 
Cuadrado-Roura and Rubalcaba-Bermejo (1998, p. 134) posit that specialisation is "foremost a historical fact" that "tends to follow its own life cycle" and the specialisation cycle may end if specialisation become uncompetitive. Other reasons may be changes in international dynamics or if "sufficient size is reached to impose a different logical pattern".

Cities are undoubtedly recognised as centres of knowledge generation, diffusion and accumulation (Fujita \& Mori, 2005). The literature is largely inconclusive as to whether agglomeration externalities arise between firms belonging to either the same or to different industries (Henderson, 1986; van Hagen \& Hammond, 1994; Glaeser, Kallal, \& Scheinkman, 1992), though. As put forward by Marshall (1890), Arrow (1962), and Romer (1986) knowledge spillovers may arise between firms within the same industry and be supported by local concentrations of a particular industry (the Marshall-ArrowRomer (MAR) type localization or 'specialization' externalities). According to the MAR type externalities, knowledge spillovers in specialized geographically-concentrated industries stimulate growth. On the other hand, the notion that industrial diversity directly contributes to agglomeration economies comes from Jacobs (the Jacobs-Porter type externalities, or economies of diversification Jacobs (1969), who argues that the most important knowledge transfers stem from variety and diversity of geographically proximate industries (Da Silva Catela, Goncalves, \& Porcile, 2010). Applied to cities, the diversification of an industry in a city helps knowledge spill-overs between firms, and therefore the growth of that city. Kolehmainen (2003) argues that the environment that agglomeration constitutes is far more complex and includes more interrelated elements to be considered, including institutional setting and behaviour of firms. Stojcic and Orlic (2015) point out that knowledge spillovers and cooperation between firms and scientific institutions can ultimately lead to increasing returns, drawing on NEG literature.

Through trade liberalisation and EU integration processes, post-transitioning Europe, has opened to structural changes. These processes can lead to increase in specialisation across key manufacturing locations, including cities. Krugman (1991) has predicted that the removal of trade barriers and European integration will bring about more industrial specialisation (or concentration) across EU and, as a consequence, more exposure to asymmetric economic shocks. Evidence from the incumbent EU members over the last two decades was not supportive of this prediction, at least at the regional level (OECD, 2004). A more evident process of structural change can be observed in the expansion of the service sector, the tertiarisation, at least across most developed regions (Marelli, 2004). However, Longhi, Musolesi and Baumont (2014) argue that the metropolitan areas and major regional centres of larger EU countries may accumulate most benefits from European integration. Urban regeneration projects in some cities (e.g. Bucharest in Romania) were connected with realisation of European Union funds (Hlaváček et al., 2016). Observing these spatial units as "the European core", with the highest probability for increasing returns to emerge through concentration of economic activities, with an econometric model Longhi, Musolesi and Baumont (2014) show how 35 metropolitan areas over the period of 19802005 have undergone structural changes due to integration and development processes. Longhi, Musolesi and Baumont's research has shown that specialisation has increased and that sectoral structures have become more similar in services. Moreover, the integration jointly with development positively influence specialisation in the sense that positive effect of development on specialisation is stronger in metropolitan areas that are better integrated with EU.

Stierle-von Schütz and Stierle (2013) use a comprehensive set of measures of concentration and specialisation for the period ranging from 1995 to 2010 to provide an overview of change in the economic structures in the EU, regarding integration processes as the trigger of change. Measures were applied to different indicators of economic activity at various sectoral breakdowns for all EU member states, including transition economies. The spatial unit of observation were regions. On an aggregated level, dynamics of the level of specialisation and concentration appeared slow, even when observed in the light of EU enlargement and in the post-2008 period of economic crisis. By observing structural traits by sectors, the authors found that in EU-15 and EU transition economies the concentration of some low-tech industries was higher and 
the concentration of high-tech industries was lower. As expected though, new member countries' concentration of high-tech industries is comparatively lower. In some regions and in some sectors there is indication of convergence of new member countries' production structures to that of EU-15, most markedly in high-tech sector manufacturing.

Longhi, Nijkamp and Traistaru (2005) researched effects of European integration on patterns of manufacturing location and specialisation for Bulgaria, Estonia, Hungary, Romania and Slovenia, accession countries at that time, over the period 1990-1999. Based on the presumption that economic integration will result in more efficient allocation of resources through structural changes and adjustment, authors carry out an econometric analysis searching for the determinants of manufacturing location. The economic geography of manufacturing in these countries was more in line with the predictions of classical and new trade theories than with predictions of NEG as it was determined by factor endowments and proximity to large markets.

Industry patterns formed across urban landscape of a country or a region will largely depend on the interplay of these opposite forces, as well as on industry- and firm-specific issues. The size of agglomeration and the economic structure may be interrelated and in some economies, mostly larger, patterns of city specialisation emerge.

Evidence on the productivity advantages that firms can appropriate by locating in larger cities and in more diversified locations can be found in the empirical literature. Firms in larger cities are overall more productive than firms in smaller cities (Combes et al., 2012; Rosenthal \& Strange, 2004), due to a number of reasons, including foremost the agglomeration economies, but also localised natural advantage, stronger worker and firm selection (Combes et al., 2012). Furthermore, productivity advantages of firms located in cities as more diversified locations are noted over firms in more specialised industrial-districttype of areas (Di Giacinto et al., 2014) provide convincing evidence for Italy). However, evidence also shows that links between efficiency and the type of agglomeration economies are to be observed in context of the countries' development level. For example, Da Silva Catela, Gonçalves, and Porcile's research (2010) on the relation between types of agglomeration economies (specialization vs. diversification) and labour productivity for 524 Brazilian municipalities in 1997 and 2007 had shown that specialised municipalities were over-performing. Authors have used finitemixture regressions and municipalities have shown polarised, with the over-performing group of municipalities being significantly specialised, while the opposite was found for the underperforming group.

\section{City Specialisation and Diversification in SEE}

\subsection{Dataset}

The main aim of this part of the paper is to discern whether patterns in the relative specialisation and diversification of manufacturing industry in 98 SEE cities exist, by constructing specialisation and diversification measures over the period 2006-2013. Indices that are used in measuring specialization (relative specialisation index) and diversity (relative diversification index) for 98 cities in six SEE countries are constructed following the work of Duranton and Puga (2000).

The empirical analysis was conducted on large dataset of 63,506 manufacturing firms observed over the period 2006-2013. The data employed in this analysis were obtained from the large pan-European firm level database Amadeus provided by Bureau van Dijk. The unit of analysis is the firm defined as a legal entity, as opposed to the establishment. The industry data were aggregated from firm-data obtained in Bureau van Dijk's Amadeus database for Central and Eastern Europe for the period 2006-2013. The geographical units are cities above 50,000 inhabitants in six SEE countries (Bosnia and Herzegovina, Bulgaria, Croatia, Serbia, Slovenia and Romania). The number of cities in each country and their share of the total national population are as follows: Bosnia and Herzegovina - 12 cities or $35.6 \%$ of the 2011 population; Bulgaria - 18 cities or $44.7 \%$ of the 2011 population; Croatia - nine cities or $35.4 \%$ of the 2011 population; Romania - 38 cities or $32.8 \%$ of the 2011 population; Serbia -17 cities or $35.7 \%$ of the 2011 population; Slovenia four cities or $24.8 \%$ of the 2011 population. To produce the city-class-size ranges, the total population of the city area was used. The greatest number of the observations, $37.1 \%$ refers to firms located in large cities (cities 
with more than 500,000 inhabitants), followed by firms located in cities between 100,000 and 249,000 inhabitants $(24.2 \%$ of the observations) and firms located in cities between 50,000 and 99,000 inhabitants (Tab. 1).

Tab. 1 displays the sectoral distribution of the observations in the sample. About $63 \%$ of the observations refer to four industry groups: food, beverages and tobacco industry, furniture, other manufactured goods and textiles, and to apparel and leather industry. Since data on the number of firms in manufacturing were not publicly available for the selected cities the total number of manufacturing firms in the country is resorted to as another option for assessing data coverage.

The analysis of manufacturing industry diversification and specialisation in the cities is based on the relation between agglomeration economies of the Marshall-Arrow-Romer type (economies of location or specialization) and the Jacobs-Porter type (economies of urbanization or diversification). Henderson's research (1997) on US cities has shown that patterns of city specialisation-size can be observed. His research shows that cities of similar sizes are often specialised in similar industries i.e. cities with population above 500,000 , considered larger cities, were more specialised in services and medium-sized cities were more specialised in manufacturing. The latter were also more specialised in matureindustries (textiles, food, pulp and paper) than in new industries on lower levels of aggregation. In his research on manufacturing industries in the U.S. and Brazil Henderson did not find urbanisation economies, but did find evidence of localisation economies explaining that by the fact that resources in manufacturing are generally not more productive in larger cities

Tab. 1: The sample - number of observations

\begin{tabular}{|c|c|c|c|c|c|}
\hline \multirow[b]{2}{*}{ Industry } & \multicolumn{4}{|c|}{ City size class } & \multirow{2}{*}{ Total } \\
\hline & $\begin{array}{l}\text { less than } \\
99,000\end{array}$ & $\begin{array}{l}100,000- \\
249,000\end{array}$ & $\begin{array}{l}250,000- \\
499,999\end{array}$ & $>500,000$ & \\
\hline Food, beverages, tobacco & 17,715 & 16,315 & 10,997 & 23,840 & 68,867 \\
\hline Textiles, apparel, leather & 15,783 & 16,292 & 9,947 & 20,677 & 62,699 \\
\hline $\begin{array}{l}\text { Wood, cork, paper, printing, recorded } \\
\text { media }\end{array}$ & 11,792 & 11,053 & 8,759 & 22,474 & 54,078 \\
\hline Coke and refined petroleum products & 128 & 124 & 12 & 281 & 545 \\
\hline $\begin{array}{l}\text { Chemicals, pharmaceuticals, rubber, } \\
\text { plastic }\end{array}$ & 7,943 & 8,336 & 5,647 & 14,308 & 36,234 \\
\hline Other non-metallic mineral products & 4,196 & 4,111 & 2,239 & 6,184 & 16,730 \\
\hline Basic metals, metal products & 14,855 & 15,772 & 9,871 & 19,796 & 60,294 \\
\hline Machinery and equipment & 3,161 & 3,909 & 2,738 & 6,399 & 16,207 \\
\hline $\begin{array}{l}\text { Computer, el. and optical products, el. } \\
\text { equipment }\end{array}$ & 3,469 & 5,490 & 3,317 & 12,056 & 24,332 \\
\hline Transport equipment & 1,534 & 2,407 & 1,087 & 2,483 & 7,511 \\
\hline Furniture, other manufactured goods & 12,588 & 16,506 & 12,491 & 25,515 & 67,100 \\
\hline \multicolumn{6}{|l|}{ Businesses by size } \\
\hline Small firms (less than 50 employed) & 82,668 & 88,653 & 60,269 & 139,904 & 371,494 \\
\hline Medium sized firms (50-250 employed) & 7,606 & 8,559 & 4,557 & 9,630 & 30,352 \\
\hline Large firms (more than 250 employed) & 2,890 & 3,103 & 2,279 & 4,479 & 12,751 \\
\hline Total & 93,164 & 100,315 & 67,105 & 154,013 & 414,597 \\
\hline
\end{tabular}


and that resources in any industry are more productive in places where there is more of similar activities (Henderson, 2003). CuadradoRoura and Rubalcaba-Bermejo (1998, p. 134) posit that "there is a close relationship between the role of a city within a hierarchical system and its degree and type of specialisation".

Looking into the specialisation first, the share of employment in city $u$ contained in industry $j$ is calculated. Since industries come in different sizes, the size of industries is normalized by their share at national level (in this case by share at the sample level for this country). In such way, the extent to which an industry $j$ is represented in city $u$ is identified. By doing so, the observed industry distribution in city $u$ is compared with that of national sample as a whole. Any value of specialization index above 1 indicates that an industry in a city area has an employment concentration above the national average. The specialisation index (normalised share or localization coefficient) is given as share of industry $i$ in city $j$ is divided by the corresponding sectoral share for whole population:

$$
S I_{i j}=\frac{x_{i j}}{x_{i}}
$$

where $i$ is the share of industry $i$ in city $j$, while $x_{i}$ is the corresponding share at the national level. The relative-specialisation index is given as:

$$
R S I_{i j}=\max _{j}\left(\frac{x_{i j}}{x_{i}}\right)
$$

The extent of city diversification is measured using the relative diversification index (RDI). The basis for its calculation is the inverse of Herfindahl-Hirschman index, which is obtained from the ratio between one and the sum of the squares of the sectoral share in city's employment. The diversification index is:

$$
D I_{i j}=1 / \sum_{j} x_{i j}^{2}
$$

DI takes the value 1 in the case where economic activity in the city under consideration is fully concentrated in a sector. Higher levels of this index suggest greater level of diversity, while smaller levels are associated with higher specialization. However, according to Duranton and Puga it is important to correct this index for differences in sectoral employment shares at the national level (Duranton \& Puga, 2000), what leads to relative diversification index. Relative diversification index (RDI) is the inverse of the sum of the absolute values of the difference between each sector's share in city's employment and its share in national employment for each city over all sectors. This index will be higher as the structure of activities in the city under configuration tends to reflect the diversity of the national economy. Relative diversification index (RDI) is given by:

$$
R D I_{i j}=1 / \sum_{j}\left|x_{i j}-x_{j}\right|
$$

Measures of specialisation and diversification were applied to the dataset used in this research. Tab. 2 displays most and least specialized cities with over 50,000 inhabitants in SEE countries, in the period from 2006-2013. Most specialized city (Burgas) is 13 times more specialised by its index value than the least specialised one (Veliko Tarnovo). Two out of 10 most specialized cities are specialised in coke and refined petroleum products industry sector and three cities in tobacco industry sector. This type of specialisation is associated to cities' natural resources or, in other words, to localised natural advantage. When considering the least specialized cities, the highest values of RSI are present among sectors of manufacturing industry. In the case of the least specialized cities (Veliko Tarnovo and Gabrovo in Bulgaria) the structure of manufacturing industry of a particular city is closer to the national.

Although not strong, the negative correlation between city specialization and its size measured by number of inhabitants $(-0.314)$ confirms previous findings that specialized cities tend to be generally smaller (Duranton \& Puga, 2000). In line with that, it should be noted that among 15 most specialized cities in SEE there is no city with more than 250,000 inhabitants. It is interesting to note that among the top 20 most specialized cities there is no Slovenian city, which could lead to the conclusion that countries with higher GDP per capita in SEE have lower share of highly 


\begin{tabular}{|c|c|c|c|c|}
\hline Rank & City & Sector & $\begin{array}{c}\text { Relative } \\
\text { specialization } \\
\text { index (RSI) }\end{array}$ & $\begin{array}{c}\text { City } \\
\text { population }\end{array}$ \\
\hline 1 & Burgas (BG) & $\begin{array}{l}\text { Coke and refined petroleum } \\
\text { products }\end{array}$ & 27.22 & 198,725 \\
\hline 2 & Bijeljina (BA) & Other transport equipment & 24.36 & 114,663 \\
\hline 3 & Ploieşti (RO) & Tobacco products & 17.99 & 209,945 \\
\hline 4 & Yambol (BG) & $\begin{array}{l}\text { Motor vehicles, trailers and semi- } \\
\text { trailers }\end{array}$ & 16.18 & 71,561 \\
\hline 5 & Giurgiu (RO) & $\begin{array}{l}\text { Coke and refined petroleum } \\
\text { products }\end{array}$ & 15.90 & 61,353 \\
\hline 6 & Blagoevgrad (BG) & Tobacco products & 15.70 & 70,293 \\
\hline 7 & $\begin{array}{l}\text { Drobeta-Turnu } \\
\text { Severin (RO) }\end{array}$ & Chemicals and chemical products & 15.18 & 92,617 \\
\hline 8 & Smederevo (RS) & Basic metals & 14.87 & 64,175 \\
\hline 9 & Nis (RS) & Tobacco products & 14.06 & 183,164 \\
\hline 10 & Galaţi (RO) & Basic metals & 13.69 & 249,432 \\
\hline 11 & Velika Gorica (HR) & Other manufacturing & 13.37 & 63,517 \\
\hline 12 & Kraljevo (SR) & Other transport equipment & 13.23 & 64,175 \\
\hline 13 & Târgoviște (RO) & Basic metals & 13.08 & 79,610 \\
\hline 14 & Banja Luka (BA) & $\begin{array}{l}\text { Basic pharmaceutical products and } \\
\text { preparations }\end{array}$ & 13.00 & 199,191 \\
\hline 15 & Mostar (BA) & $\begin{array}{l}\text { Repair/installation of machinery and } \\
\text { equipment }\end{array}$ & 12.63 & 113,169 \\
\hline$\ldots \ldots$ & - $\ldots \ldots$ & 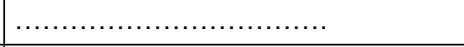 & ........... & \\
\hline 94 & Pleven (BG) & Basic metals & 2.57 & 101,978 \\
\hline 95 & Ruse (BG) & Furniture & 2.33 & 147,055 \\
\hline 96 & Plovdiv (BG) & $\begin{array}{l}\text { Printing and reproduction of } \\
\text { recorded media }\end{array}$ & 2.32 & 341,567 \\
\hline 97 & Gabrovo (BG) & Rubber and plastic products & 2.28 & 56,003 \\
\hline 98 & Veliko Tarnovo (BG) & Rubber and plastic products & 1.95 & 68,676 \\
\hline
\end{tabular}

Source: prepared by the authors on Bureau Van Dijk's Amadeus database for Central and Eastern Europe, 2006-2013.

Note: Average value of RSI over the period is given.

specialized cities, but the economy size cannot be ruled out as an alternative explanation. In most of cases of high specialization in Europe, industrial specialisation refers to the high share of textiles, food processing, and in these cases manufacturing sectors are not diverse enough to support other sectors.

According to Attaran (1986, p. 45) economic diversity is defined as "the presence in an area of a great number of different types of industries" or "the extent to which economic activity of a region is distributed among a number of categories. Much of the literature and research on economic diversity points that diverse economies are more resistant to fluctuations associated with the business cycles (Hackbart \& Anderson, 1975; Dissart, 2003), and lower output volatility is related with higher economic growth (Ramey \& Ramey, 1995). 
Distribution of 20 most specialised cities by countries and GDP per capita in SEE, 2006-2013

\begin{tabular}{|c|c|c|c|}
\hline \multirow{3}{*}{ Country } & \multirow[b]{2}{*}{$\begin{array}{c}\text { GDP per capita } \\
\text { (current prices, euro) }\end{array}$} & \multicolumn{2}{|c|}{ Cities } \\
\hline & & $\begin{array}{c}20 \text { most specialized } \\
\text { cities }\end{array}$ & $\begin{array}{c}\text { total } \\
\text { sub-sample } \\
\text { by countries }\end{array}$ \\
\hline & 2013 & 2006-2013 & 2013 \\
\hline BA & 3,569 & 3 & 12 \\
\hline$B G$ & 5,800 & 4 & 18 \\
\hline HR & 10,200 & 1 & 9 \\
\hline RO & 7,200 & 7 & 38 \\
\hline $\mathrm{RS}$ & 4,800 & 5 & 17 \\
\hline SI & 17,400 & 0 & 4 \\
\hline Total & - & 20 & 98 \\
\hline
\end{tabular}

Source: prepared by the authors on Bureau Van Dijk's Amadeus database for Central and Eastern Europe and Eurostat database, 2006-2013.

\section{Tab. 4: Most and least diversified cities in SEE, 2006-2013}

\begin{tabular}{|c|c|c|}
\hline Rank & City (country) & RDI \\
\hline 1 & Plovdiv (BG) & 2.91 \\
\hline 2 & Sofia (BG) & 2.84 \\
\hline 3 & Vratsa (BG) & 2.81 \\
\hline 4 & Belgrade (SR) & 2.77 \\
\hline 5 & Cluj-Napoca (RO) & 2.77 \\
\hline 6 & Bucharest (RO) & 2.54 \\
\hline 7 & Veliko Tarnovo (BG) & 2.34 \\
\hline 8 & Novi Sad (RS) & 2.30 \\
\hline 9 & Buzău (RO) & 2.07 \\
\hline 10 & Bihać (BH) & 1.99 \\
\hline 11 & Dobrich (BG) & 1.97 \\
\hline 12 & Gabrovo (BG) & 1.90 \\
\hline 13 & Baia Mare (RO) & 1.90 \\
\hline 14 & Stara Zagora (BG) & 1.90 \\
\hline \multirow[t]{2}{*}{15} & Varna $(B G)$ & 1.88 \\
\hline & $\ldots \ldots \ldots \ldots$ & \\
\hline 94 & Drobeta-Turnu Severin (RO) & 0.83 \\
\hline 95 & Bârlad (RO) & 0.82 \\
\hline 96 & Vranje (RS) & 0.79 \\
\hline 97 & Kranj (SI) & 0.78 \\
\hline 98 & Smederevo (RS) & 0.71 \\
\hline
\end{tabular}

Source: prepared by the authors on Bureau Van Dijk's Amadeus database for Central and Eastern Europe, 2006-2013.

Note: Capital city rank: Sarajevo (29) Zagreb (33) and Ljubljana (48). 
Tab. 4 displays 15 most diversified cities and 5 least diversified cities. Within the 10 most diversified cities there are three capital cities of the largest economies from the sample: Sofia, Beograd and Bucharest. On the other hand, the capital cities of Bosnia and Herzegovina, Croatia and Slovenia are ranked in $29^{\text {th }}, 33^{\text {th }}$ and $48^{\text {th }}$ place respectively, what can be related to the issue of the country size (in terms of population). Actually, the most diversified cities are not to be found among top ten most specialized cities. This is additionally confirmed by an indicative negative relationship between city specialization and diversification, albeit with correlation coefficient of -0.317 . However, diversity and specialisation are not exact opposites, as there are cities which are both diversified and specialised.

\section{Fig. 1: Relative diversification index and city size in terms of employment in SEE}

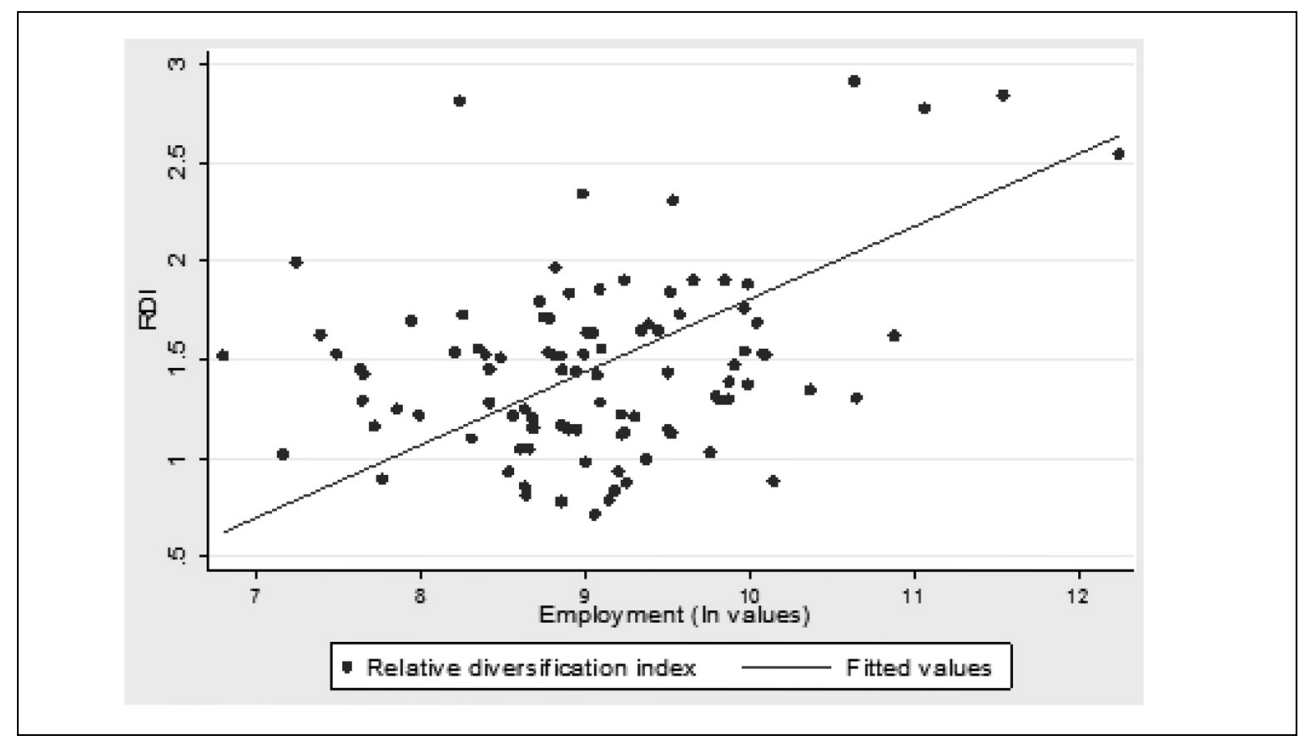

Source: Prepared by the authors based on Bureau Van Dijk's Amadeus database for Central and Eastern Europe, 2006-2013.

The relationship between city size measured by total employment in manufacturing/total population and its relative diversification index is shown on Figs. 1 and 2. There is a pretty strong positive correlation between the city size (measured by employment in manufacturing) and the relative diversification index, 0.6681 . The correlation between relative diversification index and city size measured by total population is even higher, 0.7543 and indicates that diversification increases with city size i.e. with the size of the local labour market. These results are in line with the literature (Duranton \& Puga, 2000). Also Da Silva Catela, Goncalves and Porcile (2010), measuring relative specialisation and diversification in 524 Brazilian cities confirmed that diversification increases with city size.

Larger cities have larger variety of production inputs, thus enabling concentration and economies of scales. Greater number of different industries can foster the exchange of ideas, so the firms can benefit from the generation and diffusion of the knowledge. Larger cities are usually more diversified and knowledgeintensive and have multiple specializations, while medium-sized and small cities sized cities may have just one or two, or none (Duranton \& Puga, 2000; Audretsch, 2002; Crescenzi, RodriguezPose, \& Storper, 2007; Drennan, 2002). 


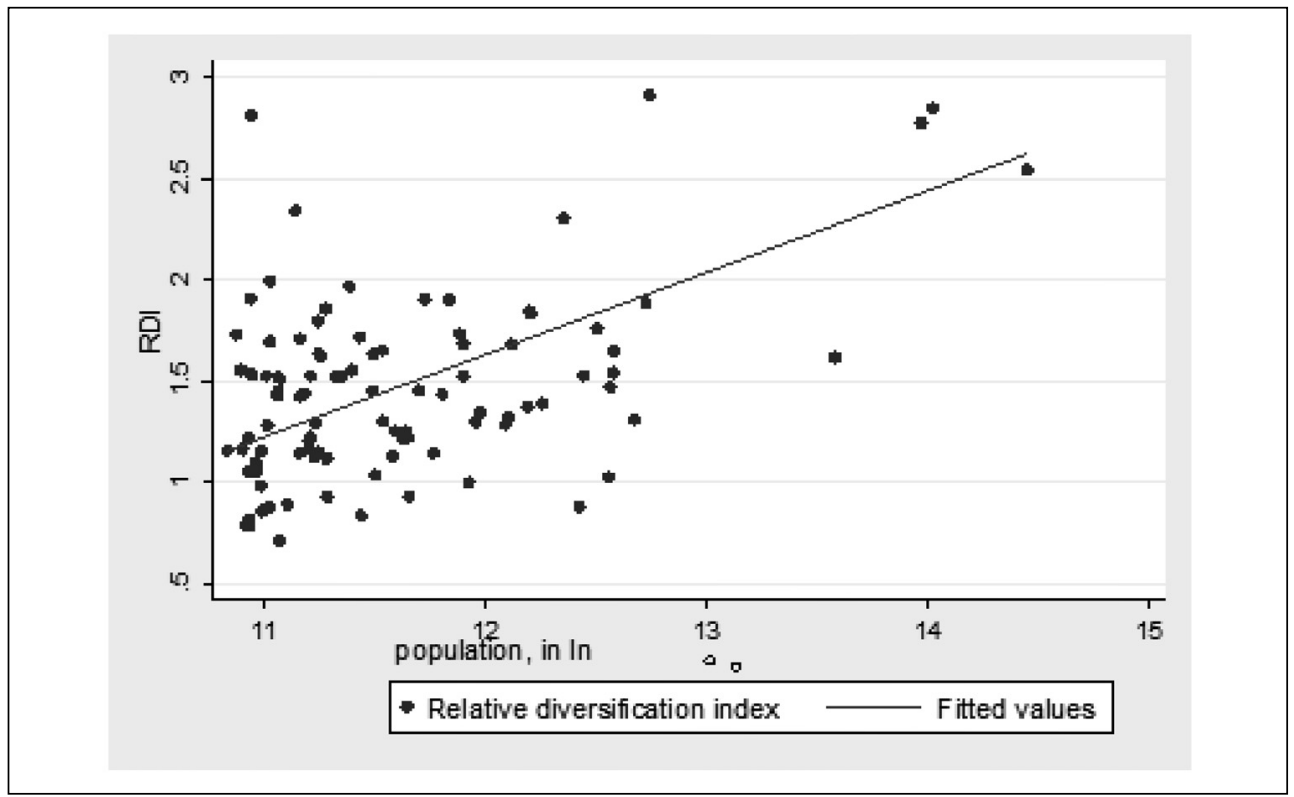

Source: Prepared by the authors based on Bureau Van Dijk's Amadeus database for Central and Eastern Europe, 2006-2013.

Glaeser et al. (1992) measured employment growth in a cross-section of manufacturing industries using data on 170 US cities between 1956 and 1987, and found that, at the cityindustry level diversity across complementary industries sharing a common knowledge base stimulates economic and employment growth. According to Feldman and Audretsch (1998) diversity across complementary industries stimulates innovation and that the degree of competition for new ideas within a city is more conducive to innovation than local monopoly.

\section{Patterns of Technological Specialisation across Cities \\ 3.1 Methodology}

This part of the analysis consists of two main steps. The goal of the first step is to analyse differences within manufacturing industry across cities in terms of their technological complexity. Thus, we use Eurostat methodology of aggregation of the manufacturing industry based on NACE Rev. 2 at 3-digit level in order to be able to analyse industry according by technological groups: high-technology (HT), medium high technology (MHT), medium lowtechnology (MLT), and low-technology (LT). The data set which has been used is compiled from Amadeus database, for the period 20062012. Sample comprises 63,506 manufacturing firms (out of 855,972 in entire population). For the analysis of differences within manufacturing industries across cities we calculate following indicators:

- share of the technology sector $i$ in city $r$ : Turnover in technological sector of a city $r$ is divided by total turnover generated by firms in that sector, where $i=\mathrm{HT}$ (High technology sector), MHT (Medium high-technology sector), MLT (Medium low-technology sector) and LT (Low-technology sector)

$$
\lambda_{i, r}=\frac{T_{i, r}}{T_{r}}
$$

- specialization index (normalised share or localization coefficient): share of sector 
$i$ in city $r$ is divided by the corresponding sectoral share for whole population:

$$
\chi_{i, r}=\frac{\lambda_{i, r}}{\lambda_{r}}
$$

- inequality index: sum over all cities of the squared differences between sectoral shares in city $r$ and the corresponding sectoral share in whole population (where $n$ is total number of cites, in this case $n=98$ ), for each technological sector

$$
\delta_{i}=\frac{\sum_{r}\left(\lambda_{i, r}-\lambda_{i, S E E}\right)^{2}}{n}
$$

A total inequality index can be computed by adding up the inequality indices pertaining to the individual sectors:

$$
\delta_{T}=\delta_{H T}+\delta_{M H T}+\delta_{M L T}+\delta_{L T}
$$

In the second step cluster analysis is used to identify the specific characteristic of homogeneous components within a sample of heterogeneous cities, and to define groups of cities on the basis of multivariate data, namely indices of manufacturing-industry specialisation, and city size using population data. This method (cluster analysis) enables the identification of the underlying patterns that exist among various spatial variables. The applied k-means cluster analysis makes it possible to identify cities which display similar development pattern, despite belonging to different states, regions or micro-regions.

The main argument in favour of this nonhierarchical clustering method (k-means) is that this method of grouping objects into clusters is more suitable when grouping units (objects) on which specific characteristics were measured, and not when grouping characteristics, i.e. variables (Johnson \& Wichern, 1992). For grouping cities into clusters, the "k-means" clustering method is used.

In k-means cluster analysis, four variables measuring city specialisation in four technological groups of manufacturing industry were used, and a variable measuring the size of the city - number of inhabitants. Cities have additionally been classified into three groups according to their importance in the national urban system, as capital-cities, as regional centres and the remainder as "other cities" or cities of local significance. Criteria for classifying cities as "regional centres" have been EU reports on second-tier cities and professional judgement of the authors based on city size and their distribution in country territory (i.e. large catchment area). The specialization indices are calculated for each level of technological intensity - high technology, medium high-technology, medium low-technology and low-technology. Although there are no rules-of-thumb about the sample size necessary for cluster analysis, the sample size to variable number relation should be evaluated before cluster analysis is calculated (by e.g. calculating the number of theoretically possible answer patterns as indicator). This sample size contains 98 elements and 5 variables and therefore meets the Forman criterion for the sample size, which suggests that the minimal sample size should include no less than $2 \mathrm{k}$ cases ( $\mathrm{k}=$ number of variables), preferably $5^{\star} 2 \mathrm{k}$ (Forman, 1984).

Decision on the number of clusters is based on the analysis of variance (ANOVA). The goal to be aimed for is that means of each cluster's individual dimension differ significantly. Generated clusters represent groups of cities that are maximally homogeneous within each cluster, and maximally heterogeneous between clusters.

\subsection{Cities' Technological Specialisation}

Results of calculation of specialisation measures are available in tables 5-7. Tab. 5 shows that high-technology industries account for only $5.5 \%$ of total turnover generated by firms in observed cities in the 2006-2013 period. Medium-low technology groups and low-technology groups have the largest shares in total manufacturing turnover, $36.2 \%$ and $35.0 \%$ respectively.

On average, the highest specialisation in HT industries can be found in Slovenian cities, followed by Croatian and Serbian cities. Bosnia and Hercegovina, on the contrary, is least specialized in high-tech sectors. Bulgaria, Bosnia and Herzegovina and Croatia are highly specialised in medium-low technologies, while Serbia and Bosnia and Hercegovina are most specialised in low-tech industries, followed by Croatia and Romania.

An index of inequality in technological specialisation in manufacturing across 98 


\begin{tabular}{l|c}
\multicolumn{1}{c|}{ Technology group } & $\mathbf{2 0 0 6 - 2 0 1 3}$ \\
\hline High technology & $5.5 \%$ \\
\hline Medium-high technology & $23.3 \%$ \\
\hline Medium-low technology & $36.2 \%$ \\
\hline Low technology & $35.0 \%$ \\
\hline
\end{tabular}

\section{Tab. 6: Specialization coefficients, 2006-2013}

\begin{tabular}{l|c|c|c|c|c|c} 
& BG & BiH & HR & SE & SI & RO \\
\hline HT & 0.61 & 0.53 & 1.43 & 1.35 & 1.83 & 0.55 \\
\hline MHT & 0.77 & 0.68 & 0.76 & 0.81 & 1.61 & 1.01 \\
\hline MLT & 1.28 & 1.08 & 1.02 & 0.75 & 0.83 & 1.02 \\
\hline LT & 0.89 & 1.19 & 1.06 & 1.34 & 0.66 & 1.04 \\
\hline
\end{tabular}

Source: authors' calculations

Note: Bulgaria is denoted as BG, Bosnia and Herzegovina as BiH, Croatia as HR, Slovenia as SI, Serbia as SE and Romania as RO.

\section{Tab. 7: Inequality indices}

\begin{tabular}{l|c|c|c|c|c} 
& HT & MHT & MLT & LT & Total \\
\hline $2006-2013$ & 0.004 & 0.039 & 0.066 & 0.055 & 0.163 \\
\hline
\end{tabular}

Source: authors' calculations

cities has been computed as well. In the observed period, the lowest level in inequality in technological specialisation across cities is recorded in HT. Stronger inequality is recorded in all other technological groups, in MLT the most.

\subsection{Clusters of Cities}

The results of the k-means cluster analysis indicate that in four different clusters of cities could be identified in analysed countries, relative to the values of the analysed variables. At the given significance level of 5 percent and empirical significance level of 0.000 for the variable HT_IS, 0.0000 for the variable MHT_IS and $0.0000,0.019$ for MLT_IS, 0.007 for LT_IS and 0.000 for city size, we may say that the means between the four proposed clusters differ significantly (Tab. 8). The best generated solution is with these four clusters.

The same can be verified by looking at the table of means and at the graph of means. Fig. 3 shows mean values of clusters for the specialization indices and city size.

Also, the mean values for the high technology specialization index (HT_IS), medium-high technology specialization index (MHT_IS), medium-low technology specialization index (MLT_IS), low technology specialization index (LT_IS) and city size (CS) indicator for generated clusters are shown in Fig. 3.

Fig. 3 illustrates the differences between clusters, i.e. peculiarities of each cluster. Cluster 1 is characterized by a relatively higher specialization in high technology and then in low 
Tab. 8: ANOVA results for 4 clusters

\begin{tabular}{l|r|r|r|r|r|r} 
& \multicolumn{2}{|c|}{ Cluster } & \multicolumn{2}{c|}{ Error } & \multirow{2}{*}{ F } & \multirow{2}{*}{ Sig. } \\
\cline { 2 - 6 } & $\begin{array}{c}\text { Mean } \\
\text { Square }\end{array}$ & df & $\begin{array}{c}\text { Mean } \\
\text { Square }\end{array}$ & df & F & \\
\hline High technology specialization & 31.437 & 3 & 0.5581 & 99 & 56.324 & 0.000 \\
\hline Medium-high technology specialization & 16.949 & 3 & 0.2478 & 99 & 68.399 & 0.000 \\
\hline Medium-low technology specialization & 1.419 & 3 & 0.4098 & 99 & 3.462 & 0.019 \\
\hline Low technology specialization & 1.707 & 3 & 0.4036 & 99 & 4.230 & 0.007 \\
\hline City Size & 45.527 & 3 & 0.6910 & 99 & 65.885 & 0.000 \\
\hline
\end{tabular}

\section{Fig. 3: Plot of means for each cluster}

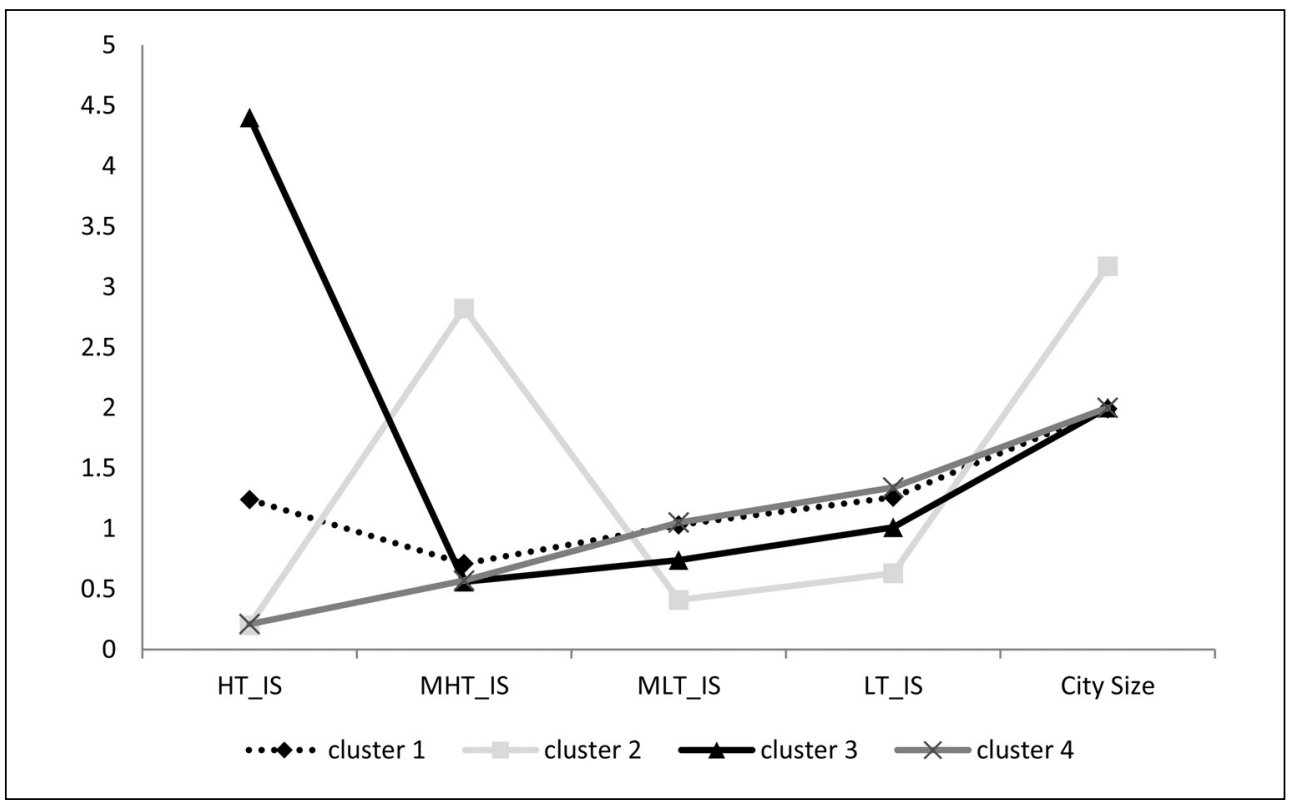

Source: authors' calculations

technology industries. This cluster comprises 35 cities. Cluster 1 contains all capital-cities apart from Slovenian capital - Ljubljana, 22 large regional urban centres (out of 25) and eight cities that may be classified under the category „other cities“ (out of 72 cities) that have similar specialization pattern. The average city population size in this cluster is 317,034 .

Cluster 2 consists of 2 regional centres and 10 cities classified under the category "other cities", with the average population size of 116,512 inhabitants. The predominant feature in cluster 2 is the highest specialization in mediumhigh tech industries. Compared to other clusters, cities in this cluster are not specialised in any of the other three technology levels.

Compared to other clusters, cluster 3 is the smallest with respect to the number of cities as well as to the population size. This cluster comprises only five cities, four of them 
being "other" cities and one is the capital-city (Ljubljana). This cluster is characterised by the highest level of specialization in high tech industries. Although the mean cluster's value for specialization in low tech industries is above 1.0 , the value is lower than that of cluster 1 and cluster 4 . The average population size of cities in this cluster is 105,922 inhabitants.

Compared to other clusters, cluster 4 consists of smaller cities with the highest specialization in low-tech and medium-low tech industries. Cluster 4 contains even 46 cities that contribute to $50.0 \%$ of the total number of the cities in the sample. Among 46 cities there is one regional centre and 45 cities classified under the category "other cities”. The average city population size in this cluster is 68,967 inhabitants.

Tab. 9 shows also the characteristics of the clusters obtained. Cluster 4 has the largest weight, since it contains 51 (50\%) of the 98 cities in the sample. Cluster 1 consists of 35 cities $(34 \%)$, cluster 2 of 12 cities $(12 \%)$ and cluster 3 of only five $(5 \%)$ of the total 98 cities from the sample. However, in terms of population size weights are different, $67 \%$ of total population covered by the sample lives in the first cluster, $21 \%$ in the fourth cluster and $8 \%$ in second cluster, while in the third cluster there are only $3 \%$ of population covered by the sample $(16.5$

\section{Tab. 9: Characteristics of the clusters}

\begin{tabular}{l|r|r|r|r|r|r|r|r} 
& \multicolumn{3}{|c|}{ Population } & \multicolumn{5}{c}{ City function } \\
\cline { 2 - 9 } & Mean & \multicolumn{1}{|c|}{ Total } & Weight & $\begin{array}{c}\text { Capital } \\
\text { city }\end{array}$ & $\begin{array}{l}\text { Regional } \\
\text { centre }\end{array}$ & Other & Total & Weight \\
\hline cluster 1 & 317,034 & $11,096,174$ & $67 \%$ & 5 & 22 & 8 & 35 & $36 \%$ \\
\hline cluster 2 & 116,521 & $1,398,257$ & $8 \%$ & 0 & 2 & 10 & 12 & $12 \%$ \\
\hline cluster 3 & 105,922 & 529,609 & $3 \%$ & 1 & 0 & 4 & 5 & $5 \%$ \\
\hline cluster 4 & 68,967 & $3,517,323$ & $21 \%$ & 0 & 1 & 45 & 46 & $47 \%$ \\
\hline Total & $\mathbf{1 6 0 , 5 9 6}$ & $\mathbf{1 6 , 5 4 1 , 3 6 3}$ & $\mathbf{1 0 0} \%$ & $\mathbf{6}$ & $\mathbf{2 5}$ & $\mathbf{7 2}$ & $\mathbf{9 8}$ & $\mathbf{1 0 0 \%}$ \\
\hline
\end{tabular}

Source: Prepared by the authors on the basis of the results obtained from the k-means cluster analysis.

\section{Fig. 4: Distribution of clusters/cities by countries}

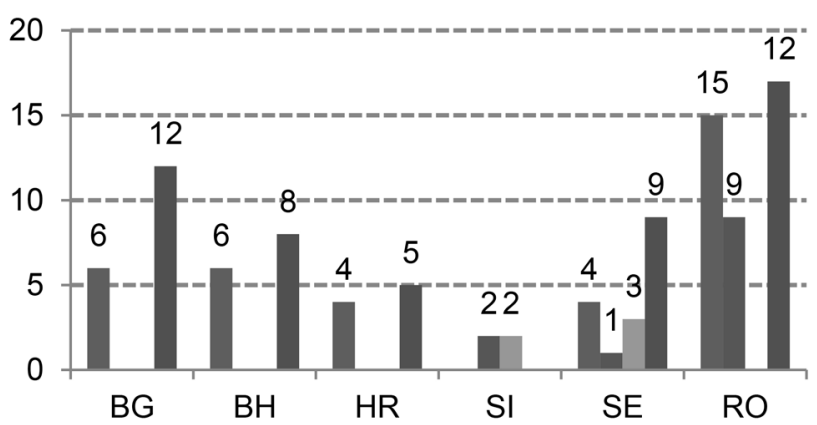

- cluster 1 cluster 2 cluster 3 cluster 4 
million people). We can see that among larger cities, capital cities and most of regional centres underlying patterns exist among clustering variables. On the other hand, smaller cities that are mostly concentrated in fourth cluster (less than 100,000 inhabitants on average), also have similar specialization pattern characterised by the highest specialization in low-tech and medium-low tech industries.

Patterns of specialization in selected countries can be discerned from Fig. 4. Bulgarian, Bosnian and Croatian cities belong to either cluster 1 or cluster 4 . The main difference between two groups of cities is in level of specialization in high-tech industries and in population size. Larger regional centres are besides being relatively moderately specialised in low-tech industries, specialized in high-tech industries. On the other hand, other group of cities (cluster 4) are smaller cities with higher specialization in low-tech industry and a very moderate specialization in medium-low tech. Slovenia has a distinct pattern of city specialization, with two Slovenian cities in third cluster and two in fourth cluster. Slovenian cities are either specialized in medium high tech industries or are highly specialized in high tech industries. Among selected countries Serbia is the only country with cities distributed across all four identified clusters. Most Romanian cities are assigned to cluster 4 , then to cluster 1 , while 9 cities belong to cluster two.

\section{Conclusions}

The main goal of this paper was to study the role of localisation (or specialisation) economies and the urbanisation (or diversification) economies in urban post-transition SEE. A particular specialisation pattern that would point to a homogenous system of cities throughout the region could not be confirmed. The results of the conducted empirical analysis show that city specialisation in manufacturing was negatively correlated to city size in SEE, but this relation has not shown particularly strong. Although greater specialisation could not be pinned to a narrow city-size-range, it can be noted though that the 15 top specialised cities in SEE belong to below-250.000-population range. However, we it can be concluded that these results partly confirm previous findings that specialized cities tend to be generally smaller (Duranton \& Puga, 2000). In addition, similarly to other countries, top-specialised cities are specialised in manufacturing closely related to natural resources such as petroleum products and tobacco, pointing to advantages arising from "first nature" geography. From the results it cannot be concluded that closeness to the EU core led to more specialisation across urban landscape of Slovenia and Croatia, but the issue of country size cannot be ruled out in these cases. The capital cities of Slovenia, Croatia and Bosnia and Herzegovina are not as nearly diversified as capital cities of larger economies in the sample that are ranked among top 10 diversified cities. Assessing city diversification for SEE has corroborated important findings from other economies on diversified economic structure being more related to larger labour markets (Duranton \& Puga, 2000). The obtained high correlations between relative diversification index and city size indicates the positive relationship between diversification and size of the city (population/ size of labour market), which is in line with the literature (Duranton \& Puga, 2000; Da Silva Catela, Goncalves, \& Porcile, 2010). The results of the second part of the analysis show that high-technology industries in manufacturing in account for only $5.5 \%$ of total manufacturing turnover generated in the selected sample of cities. Medium-low technology and low technology groups of industries in manufacturing prevail in total turnover, with $36.2 \%$ and $35.0 \%$ share, respectively. Mediumhigh technology group's share in total turnover is $23.3 \%$. Slovenian cities are on average most specialized in technologically more complex groups of industries compared to cities from other countries i.e. in high-technology industries and in medium high-technology industries, and are followed by Croatian and Serbian cities. City specialization in the prevailing technology group in SEE, in medium-low technology, is highest in Bulgarian, Bosnian and Herzegovinian and in Croatian cities. Bosnian and Herzegovinian cities are relatively most specialized in lowtech industries and least specialized in hightechnology industries. Relative specialisation of Romanian cities is roughly at the average for all technology groups, apart from high-technology industries, where Romania is least specialised along with Bosnia and Herzegovina. The lowest level in inequality in technological specialisation in manufacturing among observed cities is recorded in high tech, and the highest inequality level in technological specialisation 
is recorded in the medium low-tech group. The results of the k-means cluster analysis revealed that among larger cities, capital cities and most of regional centres underlying pattern in specialisation exists (specialization in hightech and medium high-tech industry) and this is also the case for smaller cities that have similar specialization pattern in low-tech and mediumlow tech industries.

This research was supported by a grant from the CERGE-EI Foundation under a program of the Global Development Network. All opinions expressed are those of the author(s) and have not been endorsed by CERGE-EI or the GDN.

\section{References}

Abdel-Rahman, H., \& Anas, A. (2004). Theories of systems of cities. In J. V. Henderson \& J. F. Thisse (Eds.), Handbook of Regional and Urban Economics. Amsterdam: Elsevier.

Arrow, K. J. (1962). The economic implications of learning by doing. Review of Economic Studies, 29(3), 155-172. https://doi. org/10.2307/2295952.

Attaran, M. (1986). Industrial Diversity and Economic Performance in US Areas. The Annals of Regional Science, 20(2), 44-54. https://doi.org/10.1007/BF01287240.

Audretsch, D. B., \& Feldman, M. (1996). Innovative clusters and the industry life cycle. Review of Industrial Organization, 11(2), 253-273. https://doi.org/10.1007/BF00157670.

Audretsch, D. B. (2002). The Innovative Advantage of US Cities. European Planning Studies, 10(2), 165-176. https://doi. org/10.1080/09654310120114472.

Combes, P.-P., Duranton, G., Gobillon, L., Puga, D., \& Roux, S. (2012). The productivity advantages of large cities: Distinguishing agglomeration from firm selection. Econometrica, 80(6), 2543-2594. https://doi.org/10.3982/ECTA8442.

Cuadrado-Roura, J. R., \& RubalcabaBermejo, L. (1998). Specialization and Competition amongst European Cities: A New Approach through Fair and Exhibition Activities. Regional Studies, 32(2), 133-147. https://doi. org/10.1080/00343409850123026.

Crescenzi, R., Rodriguez-Pose, A., \& Storper, M. (2007). The territorial dynamics of innovation: a Europe-United States comparative analysis. Journal of Economic Geography, 7(6), 673-709. https://doi.org/10.1093/jeg/lbm030.
Da Silva Catela, E. Y., Gonçalves, F., \& Porcile, G. (2010). Brazilian municipalities: agglomeration economies and development levels in 1997 and 2007. CEPAL Review, 101, 141-156.

Dissart, J. C. (2003). Regional Economic Diversity and Regional Economic Stability: Research Results and Agenda. International Regional Science Review, 26(4), 423-446. https://doi.org/10.1177/0160017603259083.

Di Giacinto, V., Gomellini, M., Micucci, G., \& Pagnini, M. (2014). Mapping local productivity advantages in Italy: industrial districts, cities or both? Journal of Economic Geography, 14(2), 365-394. https://doi.org/10.1093/jeg/lbt021.

Dogaru, T., Burger, M., Karreman, B., \& van Oort, F. (2014). Functional and Sectoral Division of Labour within Central and Eastern European Countries: Evidence from Greenfield FDI. Journal of Economic and Social Geography, 106(1), 120-129. https://doi.org/10.1111/tesg.12093.

Drennan, M. P. (2002). The Information Economy and American Cities. Baltimore and London: Johns Hopkins University Press.

Duranton, G., \& Puga, D. (2005). From sectoral to functional specialization. Journal of Urban Economics, 57(2), 343-370. https://doi.org/10.1016/j.jue.2004.12.002.

Feldman, M. P., \& Audretsch, D. B. (1999). Innovation in cities: Science-based diversity, specialization and localized competition. European Economic Review, 43, 409-429. https://doi.org/10.1016/S0014-2921(98)00047-6.

Fujita, M., \& Mori, T. (2005). Frontiers of the New Economic Geography. Papers in Regional Science, 84(3), 377-405. https://doi. org/10.1111/j.1435-5957.2005.00021.x.

Giffinger, R., Fertner, C., Kramar, H., \& Meijers, E. (2007). City-ranking of European Medium-Sized Cities. Final report. Retrieved April, 2016, from http://smart-cities.eu/ download/city_ranking_final.pdf.

Glaeser, E. L., Kallal, H. D., Scheinkman, J. A., \& Shleifer, A. (1992). Growth in Cities. The Journal of Political Economy, 100(6), 11261152. https://doi.org/10.1086/261856.

Hackbart, M. M., \& Anderson, D. A. (1975). On measuring economic diversification. Land Economics, 51, 374-378. https://doi. org/10.2307/3146208.

Hammond, G., \& von Hagen, J. (1994). Industrial Localization. An Empirical Test for Marshallian Localization Economies [CEPR Discussion Papers 917]. 
Henderson, J. V. (1986). Efficiency of Resource Usage and City Size. Journal of Urban Economics, 19(1), 47-70. https://doi. org/10.1016/0094-1190(86)90030-6.

Henderson, J. V. (2003). Marshall's scale economies. Journal of Urban Economics, 53(1), 1-28. https://doi.org/10.1016/S00941190(02)00505-3.

Hlaváček, P., Raška, P., \& Balej, M. (2016). Regeneration projects in Central and Eastern European post-communist cities: Current trends and community needs. Habitat International, 56, 31-41. https://doi. org/10.1016/j.habitatint.2016.04.001.

Jacobs, J. (1969). The Economy of Cities. New York: Random House.

Kolehmainen, J. (2003). Territorial agglomeration as a local innovation environment - the case of a digital media agglomeration in Tampere, Finland. [MIT Special working papers series on local innovation systems (MIT-IPCLIS-03-002)]. https://ipc.mit.edu/sites/default/ files/documents/03-009.pdf.

Lintz, G., Müller, B., \& Schmude, K. (2007). The future of industrial cities and regions in central and eastern Europe. Geoforum, 38(3), 512-519. https://doi.org/10.1016/j.geoforum.2006.11.011.

Longhi, S., Nijkamp, P., \& Traistaru, I. (2005). Economic Integration and Manufacturing Location in EU Accession Countries. Journal of International Business and Economy, 6(1), 1-22.

Longhi, C., Musolesi, A., \& Baumont, C. (2014). Modeling structural change in the European metropolitan areas during the process of economic integration. Economic Modelling, 37, 395-407. https://doi.org/10.1016/j. econmod.2013.10.028.

Marelli, E. (2004). Evolution of employment structures and regional specialisation in the EU. Economic Systems, 28(1), 35-39. https://doi. org/10.1016/j.ecosys.2004.01.004.

Marshall, A. (1890). Principles of Economics (8th ed.). London: Palgrave Macmillian.

Ramey, G., \& Ramey, V. A. (1995). Crosscountry evidence on the link between volatility and growth. American Economic Review, 85(3), 1138-1151. https://doi.org/10.3386/w4959.

Romer, P. M. (1986). Increasing Returns and Long-Run Growth. The Journal of Political Economy, 94(5), 1002-1037. https://doi. org/10.1086/261420.

Rosenthal, S. S., \& Strange, W. C. (2004). The Determinants of Agglomeration. Journal of
Urban Economics, 50(2), 191-229. https://doi. org/10.1006/juec.2001.2230.

Rumpel, P., Slach, O., \& Koutský, J. (2013). Shrinking cities and Governance of Economic Regeneration: The Case of Ostrava. E\&M Ekonomie a Management, 16(2), 113-128.

Scott, J. W., \& Kühn, M. (2012). Urban Change and Urban Development Strategies in Central East Europe: A Selective Assessment of Events Since 1989. European Planning Studies, 20(7), 1093-1109. https://doi.org/ 10.1080/09654313.2012.674345.

Stierle-von Schütz, U., \& Stierle, M. H. (2013). Regional Specialisation and Sectoral Concentration in an Enlarged EU: A comprehensive updated overview. Retrieved May 5, 2014, from http://www.infer-research. net/files_publications/WP $\% 202013$ 2\%20 -\%20Stierle\%20von\%20Schutz\%20Stierle.pdf.

Svirčić Gotovac, A. (2006). Kvaliteta stanovanja u mreži naselja Hrvatske. Sociologija i prostor, 44(171), 105-126.

Sýkora, L., \& Bouzarovski, S. (2012). Multiple transformations: conceptualising the post-communist urban transition. Urban Studies, 49(1), 43-60. https://doi. org/10.1177/0042098010397402.

Van Hagen, J., \& Hammond, G. W. (1994). Industrial localization: an empirical test for Marshallian localization economies. In Location of Economic Activities: New Theories and Evidence. London: CEPR and Consorcio de la Zona de Vigo.

Ivana Rasic Bakaric, PhD Institute of Economics, Zagreb Department for Regional Development Croatia irasic@eizg.hr

Katarina Bacic, PhD Mreža znanja Croatia bacic.keti@gmail.com

Suncana Slijepcevic, PhD Institute of Economics, Zagreb Department for Regional Development Croatia suncana@eizg.hr 


\title{
Abstract
}

\section{CITY SPECIALISATION AND DIVERSIFICATION IN SOUTH EAST EUROPE (SEE) COUNTRIES}

\author{
Ivana Rašić Bakarić, Katarina Bačić, Sunčana Slijepčević
}

The main objective of the paper is to study the role of localisation and the urbanisation (or diversification) economies in urban post-transition SEE, by constructing and analysing manufacturing specialisation and diversification measures over the period 2006-2013. The second objective of the paper is to analyse differences within manufacturing industry across cities in terms of their technological complexity. Industries are mapped across cities with over 50,000 populations (98 cities in six SEE, covering 35.3\% of the total SEE population), a population threshold that is in line with previous literature. The data were obtained from Bureau Van Dijk's Amadeus firm-level database containing, most importantly, balance sheet data and profit-and-loss account data for CEE. The analysis of manufacturing industry diversification and specialisation in the cities is based on the relation between agglomeration economies of the Marshall-Arrow-Romer type (economies of location or specialization) and the Jacobs-Porter type (economies of urbanization or diversification). Analysis results revealed that a particular specialisation pattern that would point to a homogenous system of cities throughout the region could not be confirmed. City specialisation in manufacturing was negatively correlated to city size in SEE, but this relation has not shown particularly strong. Similarly to other countries, top-specialised cities are specialised in manufacturing closely related to natural resources such as petroleum products and tobacco, pointing to advantages arising from "first nature" geography. However, diversity and specialisation are not exact opposites, as there are cities which are both diversified and specialised. The results of the second part of the analysis show that medium-low technology and low technology groups of industries in manufacturing prevail in total turnover, with $36.2 \%$ and $35.0 \%$ share, respectively. City specialization in the prevailing technology group in SEE, in medium-low technology, is highest in Bulgarian, Bosnian and Herzegovinian and in Croatian cities.

Key Words: City, specialisation, diversification, manufacturing, agglomeration economies.

JEL Classification: R00, R12, O18.

DOI: 10.15240/tul/001/2019-2-001 